\title{
WHEELCHAIR EXERCISE TESTING: COMPARISON OF CONTINUOUS AND DISCONTINUOUS EXERCISE
}

\author{
By Richard B. Whiting, M.D., F.A.C.P., F.A.C.C., Thomas E. \\ Dreisinger, Ph.D. and C. R. Hayden, M.Ed., P.T. \\ From the Cardiology Division, Department of Medicine, University of Missouri Health \\ Sciences Center, Columbia, Missouri 65212, U.S.A.
}

Summary. We have compared wheelchair exercise performed at submaximal levels in a continuous versus discontinuous format. There was a positive linear relationship between heart rate, systolic blood pressure, and $\mathrm{VO}_{2}$ with increasing workload. This was true for both modes of testing with no significant difference in heart rate, systolic blood pressure, $\dot{\mathrm{VO}}_{2}, \dot{\mathrm{Ve}}$, or $\dot{\mathrm{Ve}} / \dot{\mathrm{VO}}_{2}$. We conclude that clinical wheelchair exercise testing can be performed in a continuous format without sacrificing physiological data.

Key words: Wheelchair user; Exercises: Continuous, and discontinuous.

\section{Introduction}

EXERCISE TESTING is a well recognised and accepted means of assessing exercise capacity (Astrand, 1976; Amer. Heart Assoc. Monograph, 1975) and to some extent, detecting ischaemic heart disease (Goldschlager, I982; Ellestad, I975). The measurement of exercise capacity is a useful guide to training programmes for fitness and also for rehabilitation after cardiac surgery or myocardial infarction (DeBusk, 1979). At times exercise testing is beneficial by merely documenting the safety of strenuous activity for subjects with potential cardiovascular disease. All of these points would seem to be applicable to physically handicapped subjects as well as the able-bodied. In fact, there is some evidence that subjects who are confined to wheelchairs due to physical disabilities, have an accelerated risk of ischaemic cardiovascular disease (Hrubec and Ryder, I979).

There are many subjects who cannot perform a standard exercise test on treadmill or bicycle because of physical impairment. Therefore, there is a clear need to find alternate methods of exercise testing. Since many of these handicapped subjects travel day by day in a wheelchair, some form of wheeling exercise seems appropriate. To that end, wheelchair ergometers (Wicks et al., 1977; Dreisinger, 1978; Glaser et al., 1978) and exercise protocols (Glaser et al., I978; Whiting et al., I983; Sawka et al., I981) have been devised. Nearly all of the previous work done on wheelchair exercise has been of a physiological nature (Dreisinger and Londeree, I982) and there is a need to apply this data to the clinical setting in which actual testing of subjects with various combinations of physical and cardiovascular problems is performed. This paper addresses this adaptation by comparing

Address inquiries to: Richard B. Whiting, M.D., Division of Cardiology, University of Missouri, Health Sciences Center, One Hospital Drive, Columbia, Missouri 65212. 
exercise performed either in a continuous or a discontinuous format. The vast majority of data accumulated involving wheelchair exercise has employed a discontinous format with rest periods between successive workloads. This approach requires too much time to be clinically practical. However a continuous test with incremental loads could result in progressive, early fatigue due to the small muscle mass of the arms and therefore result in quite different heart rate, blood pressure, and oxygen uptake.

\section{Methods}

This project involved exercise testing of four male and six female ablebodied subjects, ages $22-36$, mean 29 years. The subjects body weight ranged from 49.5 to $82.7 \mathrm{~kg}$, mean $62.6 \mathrm{~kg}$. Informed consent was obtained in all cases after each subject was medically cleared for this project. Each subject had two wheelchair exercise tests performed on separate days-one in a continuous and the other in a discontinous format. The sequence of these two tests was randomised among the ten subjects.

The wheelchair ergometer used in these studies was developed at the University of Missouri (Fig. I). The frame of this device and the seat were taken from a standard wheelchair but mounted on a stationary base to elevate the wheels off the floor. An axle extended beyond the wheels themselves to support weighted flywheels. These included adjustable lead weights to correspond to a given subjects body weight and thus simulate the rotational momentum of actual wheeling. An adjustable and calibrated torque was applied to the axle to alter the resistance of wheeling. A revolution counter recorded the total number of wheel revolutions. The number of these revolutions divided by time gave angular velocity. For

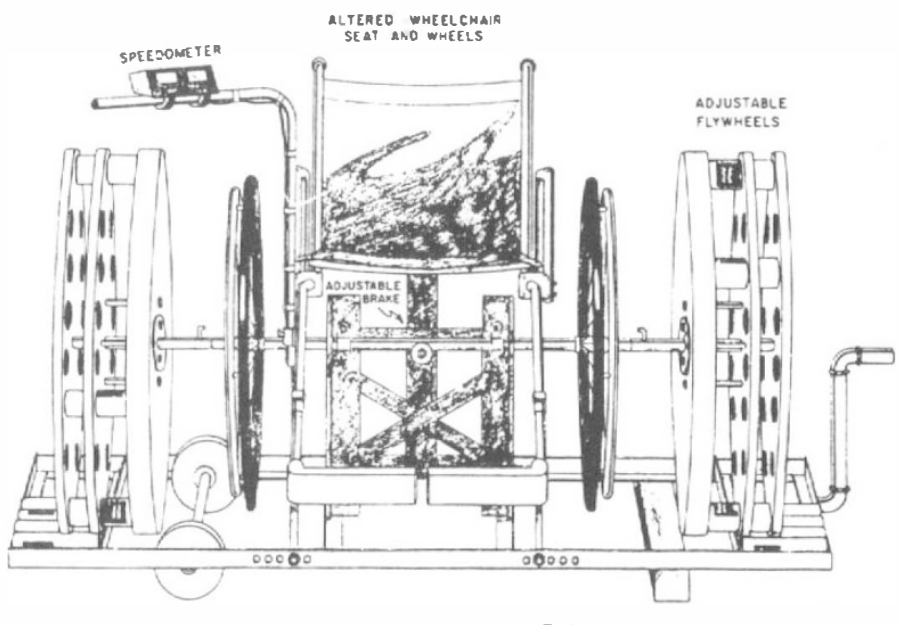

WHEELCHAIR ERGOMETER

FIG. I

Flywheels accept lead cylinders in order to adjust the weight on the axle to simulate the actual sensation of wheeling for a given subject. An adjustable brake or torque is indicated. A speedometer is mounted on a swivel to allow a position of visibility to the subject or as depicted here, a position to allow easy access to the chair itself. 
this project test subjects were required to maintain a constant angular velocity and therefore a constant speed of wheeling $(4.8 \mathrm{Km} / \mathrm{hr})$. A speedometer was therefore placed directly in front of the test subject so that he or she could maintain constant wheeling. Since angular velocity is a function of translational velocity the simulated distance travelled could easily be obtained. Work performed by the subject was then calculated using the formula:

$$
\text { WORK }=2 \pi \mathrm{T} \theta
$$

Where: $\mathrm{T}=$ the constant torque setting in kilogram-metres

$\theta=$ the number of flywheel revolutions at this torque setting

For this purpose of this study, increasing power output or workload was obtained by adjustment of the previously calibrated torque device. This torque was tested before and after wheeling at various speeds and at various workloads and found to remain accurate without evident drift.

Workloads for this particular study were arbitrarily chosen to provide moderate exertion for able-bodied subjects who were not accustomed to wheeling and to conform to workloads usually tolerated by patients in our clinical exercise laboratory. These workloads were I00, I60, I90, and 225 $\mathrm{Kpm} / \mathrm{min}$ or $\mathrm{I} 6,22,3 \mathrm{I}$, and 37 watts respectively. Each stage of the test lasted 3 minutes. The discontinuous format added 5 -minute rest periods between each stage. Thus the continuous test required 12 minutes to complete while the discontinuous one took 27 minutes. Each test was followed by a 5-minute recovery period.

The electrocardiogram was monitored during all the testing using a Hewlett-Packard recorder-oscilloscope. Heart rates were specifically noted at the end of each workload and each minute during the recovery period.

Blood pressure was recorded using a standard sphygmomanometer taped in position on the upper arm to minimise interference with arm work. Blood pressures were checked at the end of each workload and each minute during recovery.

During the continuous testing format, subjects were asked to wheel briefly with one arm as the blood pressure was obtained in the other.

Throughout each test and the recovery period, subjects breathed through a one-way valve mouthpiece with nose clips in place so that all exhaled air could be collected in meteorologic balloons at desired intervals. The total volume of exhaled air was measured (American Meter Co., model no. 5M-20I) as well as oxygen used (Beckman E-2) and carbon dioxide produced (Godart capnograph). The latter instruments were calibrated using gases of known composition and verified by the Scholander technique. Gas measurements (btps) were obtained during the last minute of each workload as well as each minute during recovery.

Means, standard deviations, and dependent $t$ tests were calculated and significance tested at the $\mathrm{p}<0.05$ level.

\section{Results}

Oxygen uptake $\left(\dot{\mathrm{V}}_{2}\right)$ increased in a linear fashion with increased workload whether the test was done in a continuous or discontinuous format (Fig. 2). The actual values of $\mathrm{VO}_{2}$ for these two modes of exercise were nearly identical at each work load. 


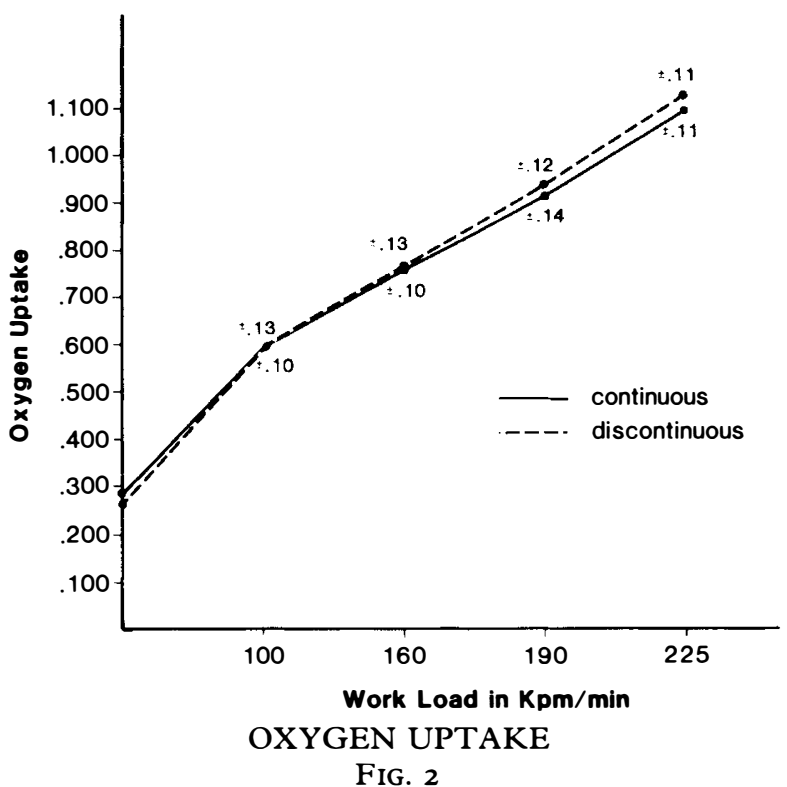

Oxygen uptakes at each workload for continuous and discontinuous testing modes are depicted together with standard deviations.

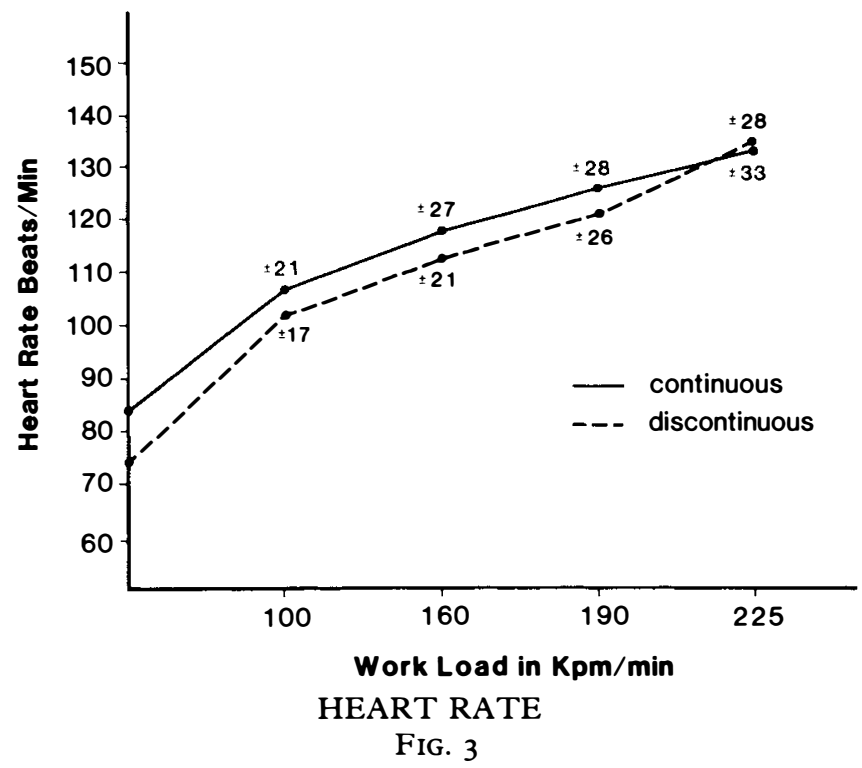

The heart rates achieved at each workload comparing continuous vs. discontinuous testing are depicted in this figure. Standard deviations are indicated.

Heart rate (Fig. 3) and systolic blood pressure (Fig. 4) also increased directly with increasing workload. There was no significant difference in heart rate or systolic blood pressure at a given workload comparing the continuous and discontinuous testing. Similarly, the so-called double 


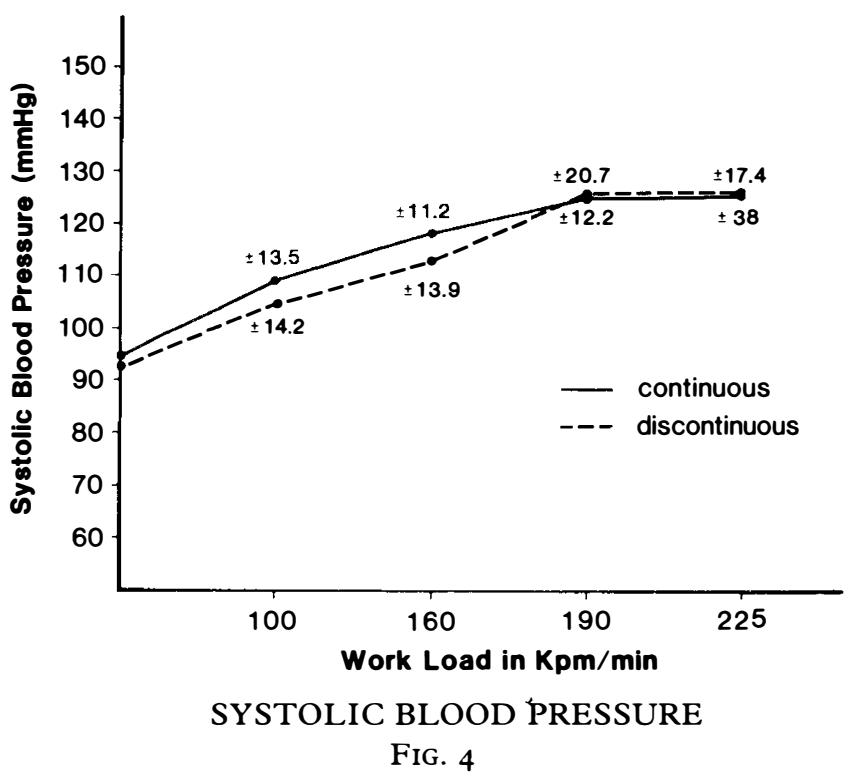

The systolic blood pressure obtained at each workload comparing continuous vs. discontinuous testing is depicted. Standard deviations are indicated.

product, that is heart rate multiplied by systolic blood pressure, was not significantly different between the two exercise test formats.

Comparison of the respiratory quotient $(\mathrm{RQ})$, minute ventilation $(\dot{\mathrm{Ve}})$, and the ratio of $\dot{\mathrm{Ve}} / \dot{\mathrm{VO}} \mathrm{O}_{2}$ obtained during continuous exercise with those obtained during the discontinuous format revealed no statistical difference. Table I shows this observation for the $225 \mathrm{kpm} / \mathrm{min}$ workload.

During the post-exercise recovery period there was no significant difference in any of the parameters examined, comparing the two exercise test formats.

TABLE I

$\mathrm{RQ}, \mathrm{V} \dot{\mathrm{e}}$, and $\mathrm{V} \dot{\mathrm{e}} / \dot{\mathrm{VO}} \mathrm{O}_{2}$ at $225 \mathrm{kpm} / \mathrm{min}$ Workload

\begin{tabular}{lcc}
\hline & Continuous & Discontinuous \\
\hline $\mathrm{RQ}$ & $\mathrm{I} \cdot 082 \pm \cdot \mathrm{I} 84$ & $\mathrm{I} \cdot 2027 \pm \cdot 060$ \\
$\mathrm{Ve}$ & $3 \mathrm{I} \cdot 963 \pm 5 \cdot 2 \mathrm{IO}$ & $33 \cdot 074 \pm 6 \cdot \mathrm{I} 84$ \\
$\mathrm{Ve} / \mathrm{VO}_{2}$ & $29 \cdot 510 \pm 5.942$ & $29 \cdot 494 \pm 5 \cdot 076$ \\
\hline
\end{tabular}

COMPARISON OF RESPIRATORY QUOTIENT, MINUTE

VENTILATION, AND THE MINUTE VENTILATION AND OXYGEN UPTAKE RATIO

\section{Discussion}

Exercise testing whether for research or clinical purposes may be performed using a discontinuous protocol with increasing workloads separated by brief rest periods. Since the subjects in this test format stop exercising at the end of each workload, recordings or physiologic parameters are easier to obtain. This is the exercise format usually used for physiological studies. Alternatively, a test protocol may be a continuous format with increasing 
workloads every few minutes until a pre-determined limit or to the subject's maximum tolerated exercise. Theoretically muscle fatigue during a continuous test format could alter physiologic responses to a given series of workloads. This may be more important for work involving the arms than the legs simply because of the muscle mass involved. Therefore this project was designed to compare oxygen uptake $\left(\mathrm{VO}_{2}\right)$, minute ventilation (Ve), $\dot{\mathrm{Ve}} / \mathrm{VO}_{2}$, heart rate, and systolic blood pressure at four workloads performed continuously or separated by 5-minute rest periods. Comparing continuous with discontinuous testing our data showed no significant difference in any of these parameters at the sub-maximal workloads used. This indicates the validity of performing clinical wheelchair exercise testing in a continuous format in order to conserve the time required for testing. Blood pressure may be followed during such testing without significant interference with wheeling or the physiologic response to the wheeling.

It is important to emphasise that this study did not involve maximal testing. The maximum heart rate achieved in this project was $134.7 \pm 30.3$

beats/minute for combined continuous and discontinuous formats. This represents approximately 85 per cent of maximal heart rates recorded in able-bodied subjects during wheelchair exercise by Wicks et al. (I977) involving two subjects and Glaser et al. (I980) with ten subjects. The peak $\dot{\mathrm{VO}} \mathrm{O}_{2}$ in our study (I.I I L/min) represents approximately 65 per cent of that in Glaser's report. Thus our study did involve moderate exercise. This would be supported by the RQ values greater than unity. In addition, the workloads used in this study are greater than those achieved in clinical testing of most handicapped persons in our laboratory who are usually limited by cardiopulmonary disease as well as a physical handicap.

\section{RÉSUMÉ}

Nous avons comparé l'exercice en voiture de malade exécuté à des niveaux en dessous du maximum dans un format qui oppose l'effort continu au discontinu. Il y avait un rapport positif linéaire entre taux de battement du coeur, tension artérielle systolique, et $\dot{\mathrm{VO}}_{2}$ avec une charge croissante d'effort. Il en était ainsi pour tous les deux modes d'essai sans différence significative de taux de battement du coeur, de tension artérielle systolique, de $\dot{\mathrm{VO}}{ }_{2}, \dot{\mathrm{Ve}}$, ou $\dot{\mathrm{Ve}} / \mathrm{V}_{2}$. Nous concluons que l'essai clinique d'exercice en voiture de malade peut être exécuté dans un format continu sans sacrifice de données physiologiques.

N.B. The expression 'voiture de malade' really corresponds to invalid carriage, but this is really what a wheelchair is. Sometimes 'fauteuil roulant' (= moving armchair) is used instead. I think 'voiture de malade' is the more usual term. (TRANSLATOR).

\section{ZUSAMMENFASSUNG}

Wir haben einen Vergleich der im Rollstuhl mit einer unter der Maximalwert stehenden Anstrengungsstufe ausgeführten Übung gemacht, und zwar im kontinuierlichen Format dem diskontinuierlichen gegenüber. Es gab ein positives lineares Verhältnis zwischen Herzschlaggeschwindigkeit, systolischem Blutdruck, und $\mathrm{V}_{2}$ mit zunehmender Arbeitslast. Das war der Fall für beide Prufmethoden ohne bedeutsamen Unterschied von Herzschlaggeschwindigkeit, systolischem Blutdruck, $\dot{\mathrm{V}} \mathrm{O}_{2}, \dot{\mathrm{V} e}$, oder $\dot{\mathrm{Ve}} / \dot{\mathrm{V}}_{2}$. Wir schliessen daraus, dass die klinische Untersuchung durch Rollstuhlübung in einem kontinuierlichen Format ausgeführt werden kann, ohne auf physiologische Angaben zu verzichten.

\section{REFERENCES}

Astrand, P. O. (I976). Quantification of exercise capability and evaluation of physical capacity in man. Prog. Cardiovasc. Dis., 19, 5I-67. 
Committee on Exercise, American Heart Association Monograph. Exercise Testing and Training of Individuals with Heart Disease or at High Risk for its Development: A Handbook for Physicians 1975.

DeBusk, R. F., Houston, N., Haskell, W., Fry, G. \& Parker, M. (1979). Exercise training soon after myocardial infarction. Am. F. Cardiol., 44, I223-1229.

Dreisinger, T. E. (1978). A training study. Doctoral thesis. University of Missouri.

Dreisinger, T. E. \& Londeree, B. R. (I982). Wheelchair Exercise: A review. Paraplegia, 20, 20-34.

Ellestad, M. H. \& Wan, M. K. C. (1975). Predicitive implications of stress testing. Follow-up of 2700 subjects after maximum treadmill stress testing. Circ., 51, 363-369.

Glaser, R. M., Foley, D. M., Laubach, L. L., Sawka, M. N. \& Suryaprasad, A. G. (1978-79). An exercise test to evaluate fitness for wheelchair activity. Paraplegia, I6, 34I-349.

Glaser, R. M., Sawka, M. N., Brune, M. F. \& Wilde, S. W. (I980). Physiological responses to maximal effort wheelchair and arm crank ergometry. F. Appl. Physiol: Respirat. Environ. Exercise Physiol., 48, 1060-1064.

GOLDSCHLAGER, N. (1982). Use of the treadmill test in the diagnosis of coronary artery disease in patients with chest pain. Ann. Int. Med., 97, 383-388.

HRUBeC, Z. \& RYder, R. A. (1979). Report to the Veterans' Administration Department of Medicine and Surgery on Service-Connected Traumatic Limb Amputations and Subsequent Mortality from Cardiovascular Disease and Other Causes of Death. U.S. Committee on Veterans Affairs U.S. Senate, U.S. Government Printing Office.

Sawka, M. N., Glaser, R. M., Laubach, L. L., Al-Samkari, O. \& Suryaprasad, A. G. (I98I). Wheelchair exercise performance of the young, middle aged, and elderly. $\mathcal{F}$. Appl. Physiol.: Respirat. Environ. Exercise Physiol., 50, 824-828.

Whiting, R. B., Dreisinger, T. E. \& ABbott, C. The clinical value of exercise testing in handicapped subjects. Southern Medical fournal (in press).

WiCKS, J. R., LymburNER, K., DiNSDALE, S. M. \& JONES, N. L. (1977/78). The use of multistage exercise testing with wheelchair ergometry and arm cranking in subjects with spinal cord lesions. Paraplegia, 15, 252-26I. 